Referencia para citar este artículo: Silva-Londoño, D. A. (2018). "Juárez no es cuartel, fuera ejército de él”. Jóvenes contra la militarización y la violencia en Ciudad Juárez. Revista Latinoamericana de Ciencias Sociales, Niñez y Juventud, 16(1), 285-296. doi:10.11600/1692715x.16117

\title{
"Juárez no es cuartel, fuera ejército de el". Jóvenes contra la militarización y la violencia en Ciudad Juárez*
}

\author{
Diana ALEJANDRA SILVA-LONDOÑo** \\ Profesora-Investigadora Universidad Autónoma Metropolitana-Iztapalapa, México.
}

Artículo recibido en diciembre 19 de 2016; artículo aceptado en abril 7 de 2017 (Eds.)

- Resumen (descriptivo): el objetivo de este artículo es realizar un análisis del movimiento social contra la militarización y la violencia en Ciudad Juárez desde una perspectiva de juventud e intergeneracional. A partir del trabajo etnográfico, las entrevistas en profundidad y la revisión hemerográfica se pretende indagar en torno a ¿cómo surge y se desarrolla el movimiento contra la militarización y la violencia?, ¿cómo participaron los/as jóvenes en dichas movilizaciones?, y ¿qué discursos, acciones y estrategias desplegaron los/as jóvenes para oponerse a la presencia militar en la ciudad? Uno de los principales hallazgos es que los/as jóvenes ocuparon un importante papel en la creación de nuevos marcos interpretativos y repertorios de acción que se opusieron tanto a los discursos oficiales que justificaba la presencia militar en la ciudad como a los discursos despolitizadores del diálogo y la paz sin justicia.

Palabras clave: juventud, militarismo, violencia, movimientos sociales, Ciudad Juárez (Chihuahua, México) (Tesauro Digital Complutense).

\section{"Juarez is not a military base: we want the army out". Young people against militarization and violence in Ciudad Juarez.}

- Abstract (descriptive): the main purpose of this paper is to investigate the social movement against militarization and violence in Ciudad Juarez - a city on the northern border of México with the U.S. -, through inter-generational and youth perspectives. The article describes the author's ethnographic work, depth interviews and hemerographic research in order to better answer questions such as, "How has the anti-militarization movement emerged and continues to develop in this context?; What discourse, actions and strategies are implemented by young people during the struggle against the military occupation in their city? The research finds that organized young people in this context occupy an important place in the creation of new interpretative boundaries and alternative repertoires of action, that stand both against the official rhetoric of justifying the military occupation, as well as against those that work to depoliticize the dialogue or reclaim "peace" without demanding justice.

Este artículo de Investigacion científica y tecnológica presenta resultados del proyecto "Nos rebelamos a la muerte. Participación juvenil contra la militarización y la violencia en Ciudad Juárez", financiado en una primera etapa por el programa Drogas, Seguridad y Democracia del SSRC, OSF, Uniandes (2012) y en una segunda etapa por el Programa de Becas Posdoctorales de la Unam, Instituto de Investigaciones Sociales (20132014). Este proyecto inició en julio de 2012 y finalizó en septiembre de 2014 (SSRC, may 25, 2012, Craig Calhoun, president). Una versión preliminar fue presentada en la II Bienal Iberoamericana de Infancias y Juventudes. Manizales, Colombia, 10 de Noviembre de 2016. Área: sociología; subárea: otras sociologías.

** Economista de la Pontificia Universidad Javeriana, Maestra en Ciencias Sociales por la Flacso-México y Doctora en Ciencia Social con especialidad en Sociología por El Colegio de México. Profesora-Investigadora Visitante de la Universidad Autónoma Metropolitana Iztapalapa. Orcid: http://orcid.org/0000-0002-8632-7471. Índice H5: 3. Correo electrónico: diana.alejandra.silva@gmail.com 
Key words: youth, militarism, violence, social movements, Ciudad Juárez (Chihuahua, México) (Complutense Digital Thesaurus).

\section{“Juarez não é quartel: fora militares!". Juventude organizada contra a militarização e a violência na Cidade de Juarez}

- Resumo (descritivo): o objetivo desse artigo é analisar o movimento social contra a militarização e a violência na Cidade de Juarez (Fronteira com Estados Unidos, ao Norte do México), do ponto de vista da juventude e intergeracional. A partir do trabalho etnográfico, realização de entrevistas à profundidade e revisão hemerográfica, pretende-se indagar: Como esse movimento contra a militarização surge e se desenvolve; e quais discursos, ações e estratégias foram implantadas pela juventude, em franca oposição à presença militar nessa cidade fronteiriça. O principal argumento que emerge do presente estudo pode ser resumido da seguinte maneira: A juventude, nesse contexto, ocupa um importante papel na criação de novos marcos interpretativos, por sua vez, relacionados a repertórios alternativos de ação política, que se opõe de forma rotunda, tanto aos discursos oficiais que justificam a presença militar, como àqueles despolitizadores do diálogo e de uma ideia de "paz" sem (outra ideia de) justiça.

Palavras-chave: juventude, militarismo, violência, movimentos sociais, Ciudad Juárez (Chihuahua, México) (Tesauro Digital Complutense).

-1. Introducción. -2. Cronotopías de la violencia en Ciudad Juárez. -3. Protagonismo juvenil en los movimientos sociales desde una perspectiva de juventud e intergeneracional. Coordenadas teórico-metodológicas. -4. Movimiento Social contra la militarización y la inseguridad en Ciudad Juárez. -5. Discursos, estrategias y acciones impulsadas por los y las jóvenes en contra de la militarización y la violencia. -6. Conclusiones. -Lista de referencias.

\section{Introducción}

Este artículo busca analizar el movimiento contra la militarización y la violencia en Ciudad Juárez desde una perspectiva de juventud e intergeneracional, teniendo en cuenta que los y las jóvenes han tenido un importante papel en su interior pese a la imagen que predomina de ellos como actores apáticos y desinteresados políticamente. Como mostraremos, la participación de los/as jóvenes ha sido particularmente visible en el bloque de organizaciones estudiantiles de izquierda que se opusieron a la militarización y a la colaboración con el Estado, en el contexto de la mal llamada "guerra contra el narcotráfico", algunos de los cuales confluyeron posteriormente en el movimiento \#yosoy 132.

Consideramos que este trabajo puede contribuir a llenar un importante vacío en los estudios que buscan conocer cómo la violencia exacerbada y normalizada en México está impactando en los mundos juveniles y cómo esta está limitando las posibilidades de agencia y las formas de acción que van desde aquellas que se despliegan en el ámbito de la vida cotidiana y cultural hasta la acción colectiva y la movilización política. En este sentido es un estudio que se concentra en el protagonismo juvenil atendiendo a la necesidad de conocer el modo en que los y las jóvenes están produciendo visibilidad en un contexto de violencia sistemática y militarización de la seguridad pública como el ocurrido en Ciudad Juárez, aplicable a otros contextos latinoamericanos

Nos proponemos analizar: ¿cómo surge $\mathrm{y}$ se desarrolla un movimiento contra la militarización y la violencia en Ciudad Juárez?, ¿cómo participaron los y las jóvenes en dichas movilizaciones?, ¿qué discursos, acciones y estrategias desplegaron para oponerse a la presencia militar en la ciudad? Este artículo se fundamenta en el trabajo etnográfico realizado entre octubre de 2012 y septiembre de 2013, que incluye las entrevistas en profundidad y la revisión hemerográfica sobre las movilizaciones 


\section{“JUÁREZ NO ES CUARTEL, FUERA EJÉRCITO DE ÉL". JÓVENES CONTRA LA MILITARIZACIÓN Y LA VIOLENCIA EN CIUDAD JUÁREZ}

realizadas en la ciudad entre 2008 y 2011. Este texto se organiza en cinco partes. En la primera, presentaremos brevemente el contexto de violencia sistemática y de implementación del Operativo Conjunto Chihuahua ${ }^{1}$. En la segunda parte, planteamos las coordenadas teórico-metodológicas sobre la que se sustenta este estudio. Posteriormente, describiremos la emergencia del movimiento social en contra de la militarización y la inseguridad. En el cuarto apartado nos concentraremos en los discursos, acciones y estrategias de los y las jóvenes aglutinados en las organizaciones de izquierda. Por último, finalizamos con unas breves conclusiones.

\section{Cronotopías de la violencia en Ciudad Juárez}

Ciudad Juárez está ubicada en la frontera entre Estados Unidos y México. A finales de la década de 1960 se convierte en lugar para la aplicación del modelo de exportación conocido como la industria maquiladora, que incorporaría a amplios sectores de población provenientes de todas las geografías del país. Durante la década de los 1990, se hace tristemente célebre desde que comenzaran a registrarse los casos de feminicidio (Monárrez-Fragoso, 2009). De manera más reciente, ha sido una de las ciudades más afectadas por la violencia en México desde el inicio de la mal llamada "guerra contra el narcotráfico" promovida por el presidente Felipe Calderón (20062012). Esta circunstancia le valió por tres años consecutivos el primer lugar como una de las ciudades más violentas del mundo. Entre las principales víctimas se cuentan jóvenes, con lo cual cual algunos investigadores comenzaron a referirse al juvenicidio como categoría analítica (Nateras, 2016; Valenzuela, 2015). Asimismo se intensificaron las detenciones arbitrarias principalmente a jóvenes (Cárdenas, 2014) y

\footnotetext{
1 Operativo de combate al narcotráfico que inició en marzo de 2008 con el despliegue de 2026 efectivos de las fuerzas armadas y 425 agentes de la Policía Federal y de la Procuraduría General de la República (Meyer, Brewer, \& Cepeda, 2010). Posteriormente, incrementó el número de efectivos con 1400 soldados adicionales en junio de 2008 y 5332 en marzo de 2009. En abril de 2010 se transfirió gradualmente el mando del operativo a la Policía Federal con el apoyo de 5000 efectivos y de 2500 Policías Municipales (Moloeznik, Shirk, \& Suarez de Garay, 2011)
}

se estableció un toque de queda para menores de edad como una estrategia para reducir la violencia entre pandillas.

En respuesta a esta situación, se generó una fuerte indignación que impulsó el florecimiento de una corriente crítica proveniente de una amplia diversidad de agrupaciones juveniles, tanto desde el ámbito cultural como desde la militancia política que tuvieron un papel protagónico en el movimiento social contra la militarización y la violencia en la ciudad. Algunas de estas agrupaciones ya existían previamente y también nacieron algunas nuevas que desafiaron la retórica oficial que insistía en encasillar a los jóvenes dentro de las categorías de víctimas o victimarios, mostrando su capacidad para la creación de proyectos colectivos. Este proceso, se enmarca en un nuevo ciclo de movilizaciones sociales que tienen como protagonistas a los y las jóvenes ${ }^{2}$, en donde observamos la "construcción intergeneracional de singularidades, pluralismos, visiones alternativas y resistencias frente a los modelos predominantes de participación y de representación de lo político" (Agudelo-Ramírez, Murillo-Saa, EcheverryRestrepo, \& Patiño-López, 2013, p. 589).

\section{Protagonismo juvenil en los movimientos sociales desde una perspectiva de juventud e intergeneracional. Coordenadas teórico- metodológicas}

Para acercarnos a la comprensión del protagonismo juvenil en el movimiento social contra la militarización y la violencia desde

\footnotetext{
2 El momento en el que emerge este movimiento es distinto a otros movimientos locales donde tuvieron un importante protagonismo los y las jóvenes. Entre ellos, el movimiento estudiantil de 1968 (Pedraza, 2008), el movimiento guerrillero particularmente en el Comando Lacandones que posteriormente se suma a la Liga 23 de septiembre en 1973. En 1975 surgen las Comunidades Eclesiales de Base que dan nacimiento a un importante grupo de organizaciones sociales protagonizados por jóvenes a inicio de la década de 1980, alejados de las estrategias tradicionales utilizadas por el PRI (Castillo, 2009). En 2003 en las aulas de la UACJ nace el movimiento estudiantil "fronteras por la paz" en un contexto de movilizaciones a nivel mundial en contra de la invasión a Irak por parte de Estados Unidos y el Reino Unido, respaldada por países aliados menores. Es un movimiento que nace en el contexto estudiantil pero al que se unen colectivos y personas provenientes de agrupaciones de izquierda. A medida que fue creciendo, este movimiento se hace binacional cuando se vincula con estudiantes provenientes de Utep El Paso, Texas (Murillo, 2014).
} 
una perspectiva de juventud y generacional en Ciudad Juárez, en este apartado definimos los conceptos de juventud, generación y de movimientos sociales.

Como categoría del análisis social, particularmente en el campo de las ciencias sociales y las humanidades, la juventud es definida como una construcción social históricamente situada en la cual cada sociedad, e incluso al interior de la misma, organiza la transición de la infancia a la vida adulta. Por ello, el contenido y las formas de dicha transición es enormemente variable y depende del modo en que se articula con la estructura social y el significado y las representaciones sociales que se le atribuyen a la misma, entendiendo a la juventud como una categoría relacional (Reguillo, 2000; Urteaga, 2010).

Teniendo en cuenta que el movimiento social contra la militarización y la violencia en Ciudad Juárez, fue un movimiento con un importante protagonismo juvenil, nos interesa develar las relaciones intergeneracionales que allí se gestaron. Para ello, recurrimos a la noción de generación como categoría de apoyo para la comprensión del concepto de juventud. Siguiendo a Alvarado, Martínez y Muñoz (2009), entendemos la generación como un concepto que "remite a la edad, pero como una producción cultural, social e histórica. Así la adscripción suscitada por una determinada generación (...) se perfila como un horizonte continuo que persevera en su intento de intensificar la identificación juvenil y con ello la emergencia colateral de diferentes conflictividades, tanto en sí misma, como con otras generaciones" (Alvarado et al., 2009, p. 99). En este sentido, la noción de generación no se reduce a la condición etárea, sino que implica necesariamente la existencia de una problemática compartida que posibilita la identificación, el reconocimiento y la constitutución de un nosotros, que se convierte en un potente detonador de subjetividades políticas que surge en respuesta a un sistema de dominación excluyente y adultocéntrico (Vommaro, 2013). Un elemento nodal en la construcción de una problemática compartida de los y las jóvenes que participaron en el movimiento fue la necesidad de defender la vida frente a la criminalización y la violencia sistemática.

Teniendo en cuenta lo anterior, en este artículo damos cuenta del lugar que ocuparon los jóvenes al interior del movimiento, develando las relaciones que se dieron con otros actores sociales involucrados identificando los marcos para interpretar la situación y los repertorios de acción desplegados. El movimiento social estudiado, lejos de ser un movimiento con valores, intenciones y fines unificados, estuvo conformado por un "sistema de acción multipolar" (Melucci, 1991) en el que actuaron diferentes marcos de interpretación en torno a: las causas de la violencia, la decisión de colaborar u oponerse a la acción del Estado, la demanda de militarizar o desmilitarizar la seguridad pública y la relación con el contexto local, nacional e internacional.

$\mathrm{Si}$ bien los movimientos sociales se caracterizan por esta heterogeneidad de actores sociales involucrados con formas $y$ estrategias de acción diferenciadas, comparten un núcleo duro de reclamos. Una definición de movimientos sociales concisa y útil para mostrar esto, es aquella que los define como "desafíos colectivos plateados por personas que comparten objetivos comunes y solidaridad en una interacción mantenida con las elites, los oponentes y las autoridades" (Tarrow, 1997, p. 21). En la labor de sostenener una interacción a lo largo del tiempo juega un papel central la adopción e innovación de repertorios de acción, así como la elaboración de marcos interpretativos.

Por repertorios de accion entendemos el "conjunto limitado de rutinas aprendidas, compartidas y actuadas, a través de un proceso de elección relativamente deliberado (...) son creaciones culturales aprendidas, pero no descienden de la filosofía abstracta ni toman forma como resultado de la propaganda política, sino que surgen de la lucha (...). Sin embargo, en un momento particular de la historia la gente aprende una cantidad bastante limitada de modos alternativos de acción colectiva" (Tilly, 2002 , p. 31). Atender a los repertorios de acción nos permite dar cuenta de las continuidades y transformaciones de las formas de acción colectiva escenificada públicamente y las 


\section{“JUÁREZ NO ES CUARTEL, FUERA EJÉRCITO DE ÉL". JÓVENES CONTRA LA MILITARIZACIÓN Y LA VIOLENCIA EN CIUDAD JUÁREZ}

maneras de visibilizar el conflicto expresado por el descontento causado por la violencia y la inseguridad en la ciudad. Por su parte, el concepto de marcos interpretativos en los movimientos sociales, nos permite aprehender "aquellos aspectos simbólico-discursivos de significar la realidad social (y semantizarla) que desarrollan estos como forma de constituir comunidad y legitimar su accionar" (Aguilera, 2016, p. 276).

Teniendo en cuenta todo lo anterior, metodológicamente proponemos la construcción de una narrativa analítica (Somers, 1994). Mediante este tipo de narrativa buscamos reconstruir una secuencia de sucesos ordenados en el tiempo, basada en el análisis de las acciones, interacciones estrategias y repertorios por parte de los actores sociales involucrados, enfatizando en el papel que tuvieron los y las jóvenes en el movimiento social contra la violencia y la inseguridad en Ciudad Juárez. De este modo, establecemos una serie de puentes entre los datos que recabamos de la revisión hemerográfica, la investigación documental, la observación participante $y$ las entrevistas en profundidad, con una serie de conceptos que nos permitan identificar en términos teóricos la secuencia de acciones, interacciones y los contextos de situación. Más allá de buscar una explicación causal cristalina, mediante la narrativa ofrecemos una explicación plausible para los casos y eventos, que nos permita comprender cuáles fueron las dinámicas de la acción colectiva a través del tiempo. Las personas entrevistadas fueron seleccionados inicialmente mediante una muestra de oportunidad, contactando a los/ as principales protagonistas y posteriormente se extendió a otros/as actores a partir de una muestra evaluada (Gúber, 2004).

\section{Movimiento social contra la militarización y la inseguridad en Ciudad Juárez}

Siguiendo el trabajo de Díaz (s. f.), podemos entender el movimiento social contra la militarización y la inseguridad en Ciudad Juárez a partir de su clasificación en tres grandes bloques teniendo en cuenta las diferencias en su ideología, sus estrategias y las demandas de sus protagonistas. El primero de ellos corresponde a los grupos de la izquierda aglutinada en el Comité Universitario de Izquierda, compuesto por zapatistas, anarquistas y socialistas, quienes desde la implementación delOperativo Conjunto Chihuahua, señalaron que esto representaba un pretexto para reprimir a los movimientos sociales e intimidar a la población. Este bloque se articula con militantes de izquierda provenientes de las guerrillas y el movimiento estudiantil de 1968. Este grupo tuvo una importante presencia en las calles, mediante la realización de marchas, plantones, foros y las "Kaminatas contra la Muerte"3. Los repertorios de acción de este grupo de organizaciones combinó formas tradicionales de protesta con acciones carnavalescas y performáticas que tuvieron como escenario privilegiado los espacios públicos. La mayoría de las reuniones que realizaron utilizaron el método asambleario y se realizaron en espacios públicos.

En el segundo bloque, encontramos a las organizaciones no gubernamentales y de derechos humanos ligadas a las comunidades eclesiales de base. Cuando estalla la crisis de 2008, este bloque actuó como un grupo de articulación con el primer bloque y con organizaciones académicas, empresariales y de derechos humanos locales, nacionales e internacionales a través de lo que se denominó la Asamblea Ciudadana Juarense. Lo anterior posibilitó la realización de grandes eventos nacionales como el Tribunal Permanente de los Pueblos (TPP) y la firma del Pacto Ciudadano en el marco de la Caravana del Consuelo, de la Esperanza y de la Paz encabezada por Javier Sicilia del Movimiento por la Paz con Justicia y Dignidad y más de 250 organizaciones de todo el país.

Por último, el tercer bloque estuvo compuesto por empresarios, agrupaciones profesionales, scouts y algunos sectores de la iglesia católica que se articularon en torno a

\footnotetext{
3 Las caminatas contra la muerte fueron encabezadas por Luis K'Fong en Chihuahua, reconocido activista quien propuso salir a caminar como una acción de resistencia considerando el importante esfuerzo físico que ello representaba pues usaba muletas y un aparato ortopédico en una de sus piernas. Estas caminatas se realizaron en Chihuahua y Ciudad Juárez, en esta última ciudad hasta por 11 ediciones.
} 
Juarenses por la Paz. Entre las organizaciones que participaron se destaca la Asociación de Maquiladoras, el Observatorio Ciudadano y el Comité Médico Ciudadano. Este bloque solicitó en principio la presencia de las fuerzas militares en la ciudad ante la impunidad, la incapacidad y la complicidad de las policías. Por lo general las reuniones de este bloque se hicieron a puertas cerradas y en espacios privados. Aunque estuvieron de acuerdo con la intervención militarizada, poco a poco fue creciendo el malestar por la presencia del ejército.

\section{Villas de Sálvarcar: la gota que derramó el vaso}

Pese a los distintos objetivos, posicionamientos políticos y formas de acción de los distintos bloques que actuaron frente al contexto de creciente violencia e inseguridad en Ciudad Juárez, los acontecimientos que a continuación se presentan mostraron cómo en ciertos momentos la indignación y el sentimiento de injusticia pueden alinear el sistema de acción multipolar y los marcos de interpretación diferenciados (Cefaï, 2008), produciendo el acercamiento momentáneo entre distintos grupos que conformaron el movimiento y con ello el logro de consensos precarios e inestables.

El 30 de enero de 2010, fueron asesinados en el fraccionamiento Villas de Salvárcar, cuatro adultos y 12 jóvenes entre los 15 y los 19 años. Este hecho evidenció la criminalización de las víctimas civiles, principalmente jóvenes, a quienes Calderón nombraba como "daños colaterales", cuando declaró en rueda de prensa que los jóvenes habían sido asesinados porque eran pandilleros. También visibilizó la importante oposición por la presencia del ejército en las calles, que ya se había expresado por activistas y organizaciones de derechos humanos pero que ya se extendía hacia los sectores medios y empresariales que otrora pedían la intervención militar.

Estos hechos mostraron que la masacre no era producto de un enfrentamiento entre cárteles contrarios, como se suponía que ocurría. También quedo en evidencia la falta de eficiencia de las fuerzas militares, pese a ser una de las ciudades más militarizadas del país. Todo esto impulsó un importante debate a nivel nacional, que cuestionó la estrategia de seguridad adelantada por el gobierno de Calderón. A esta oleada de indignación le siguieron múltiples movilizaciones. En Facebook se creó el grupo "Yo repudio la masacre en Juárez" y en twitter el hashtag \#MasacreEnJuarez. En tres días, el grupo consiguió más de 10 mil miembros. Por esta vía se convocaron a distintas movilizaciones, entre ellas el "éxodo por la paz", realizada el 8 de febrero de 2010 para solicitar asilo humanitario multitudinario (Gaytán, Olivas, Minjares, \& Coronado, 2010). También se convocó a una movilización el 9 de febrero organizada por FNCR, Asamblea Ciudadana Juarense, el Comité Universitario de Izquierda y la Liga Socialista Revolucionaria. Asimismo se convocó a la marcha del "Coraje, el dolor y el desagravio en Ciudad Juárez" el 13 de febrero que encabezaron familiares de los jóvenes asesinados y en donde participaron personas y colectivos de diferentes tendencias y posiciones políticas.

Por su parte, organizaciones de derechos humanos como la Red Mesa de Mujeres de Ciudad Juárez y el Movimiento Pacto por la Cultura (Ballinas, 2010) convocaron a una rueda de prensa para manifestar el fracaso de la estrategia militar como salida a la crisis de violencia e inseguridad e hicieron un llamado para salir a las calles y acompañar a las familias en la exigencia de justicia. Asimismo, organizaciones ligadas al ámbito empresarial, como el Consejo Ciudadano para la Seguridad Pública y la Justicia Penal, las asociaciones de Comerciantes de las Centrales de Abasto y el Observatorio Ciudadano de Ciudad Juárez le exigieron a Felipe Calderón que responierad si tenía capacidad o no para llevar la paz a la ciudad y mencionaron la posibilidad de solicitar a la ONU el envío de una misión de paz ante el clima de indefensión generalizado (Castillo, \& León, 2010). Como resultado de la presión de las organizaciones y personas a 


\section{"JUÁREZ NO ES CUARTEL, FUERA EJÉRCITO DE ÉL".

nivel local, estatal y nacional, fue inevitable la visita de Felipe Calderón a Ciudad Juárez el 11 de febrero de $2010^{4}$.

Tras la masacre y el debate generalizado sobre la militarización de la seguridad pública y las movilizaciones sociales, se reemplazó al Ejército por Policías Federales y posteriormente por Policías Municipales. De manera paralela, se implementó el programa federal "Todos Somos Juárez", con la participación del gobierno federal, estatal y municipal ${ }^{5}$.

\section{Discursos, estrategias y acciones impulsadas por los y las jóvenes en contra de la militarización y la violencia}

Los y las jóvenes que se movilizaron participaron principalmente en el primer bloque compuesto por organizaciones de izquierda universitaria provenientes de agrupaciones socialistas, zapatistas y anarquistas. Este grupo de activistas generó nuevos marcos de interpretación y repertorios de acción que fueron posteriormente adoptados por otros grupos al interior del movimiento, particularmente en aquellos momentos en donde no era posible el diálogo y la negociación con el gobierno.

Una de las estrategias discursivas que emplearon fue la de aludir constantemente a la "supuesta guerra contra el narco" contradiciendo el discurso oficial que insistía en que la militarización era una respuesta necesaria frente a la guerra. Los y las jóvenes de este bloque de organizaciones insistieron permanentemente en que no era una guerra, sino un ataque unilateral a la población civil, particularmente a jóvenes de estratos socioeconómicos bajos. En los primeros análisis de coyuntura, identificaron una serie de razones para mantenerse en oposición a la militarización, como nos comparte Gero Fong:

Yo por ejemplo hablé de cómo se empezaron en Chihuahua a poner

4 Esta fue la tercera visita de Felipe Calderón a Ciudad Juárez. Se realizó en el centro de convenciones Cibeles donde se convocó a empresarios, organizaciones de derechos humanos y organización no gubernamentales previamente seleccionadas.

5 Este programa, se estructuró en seis ejes: 1) seguridad pública 2); economía; 3) promoción al empleo; 4) salud; 5) educación, cultura y deporte; 6) desarrollo social; mediante estos se implementaron 160 acciones. Para ello, se invirtieron 263 millones de dólares en 2010 y 138 en 2011 (en total más de 3300 millones de pesos mexicanos). cámaras, a hacer grupos especializados militarizados, todas estas tendencias confirmaban claramente la cuestión de que se estaba avanzando a una solución militarizada de la crisis. Entonces todo esto se vino a confirmar con la militarización como respuesta a la guerra y entonces eso determinó que los que hicieran el núcleo de resistencia contra la militarización éramos básicamente los radicales, o sea, en las primeras reuniones lo primeros que estaban ahí era, de aquella vieja guardia que te decía de los setentas, tendencias maoístas, guerrilleras, comunistas y los jóvenes socialistas de organizaciones más nuevas. (Gero Fong, activista Frente Plural Ciudadano, Entrevista realizada el 15 de marzo de 2013).

Desde las primeras movilizaciones, fueron hostigados, mediante acosoyseguimientos en sus viviendas. Sin embargo optaron por denunciarlo para mostrar la represión que el ejército estaba ejerciendo sobre los movimientos sociales. Esto implicó la búsqueda de otras estrategias como la generación alianzas con otras organizaciones locales, estatales y nacionales para denunciar la situación vivida. Esto les llevo a revisar otras experiencias latinoamericanas y entender que se trataba de una estrategia frente a la crisis de legitimidad vivida por el presidente Calderón.

La oposición a la militarización de la ciudad se fortalece cuando asesinan a Manuel Arroyo Galván, profesor de la UACJ. Tras este acontecimiento se vincularon con otras organizaciones, particularmente con las pertenecientes al segundo bloque compuesto por organizaciones no gubernamentales para conformar la "Asamblea Ciudadana Juarense". La interacción entre actores y organizaciones con marcos interpretativos diferenciados produjo una serie de tensiones y negociaciones. Al respecto uno de los participantes nos comenta:

Unos decían: esta manifestación debe ser también en contra de la militarización y debe ser crítica de la estrategia del gobierno, y los otros decían: estamos de acuerdo en que debe de haber crítica pero pensamos que eso 
puede convertir la manifestación en un enfrentamiento con el ejército y con las fuerzas (...) entonces lo que se debe pedir es la paz y no decirle nada a los militares. Y se discutió y se discutió, y se llegó a un consenso: va a haber un pronunciamiento muy claro en que la guerra que está haciendo el gobierno es una guerra contra el pueblo y se va a decir que exigimos el fin de la militarización y etc. a cambio de que vamos a marchar pacíficamente, que vamos a llegar al puente y que no le vamos a gritar consignas directas a los militares, no se les va a insultar ni nada, a cambio de que se leyera el pronunciamiento, era como la negociación. (Gero Fong, activista Frente Plural Ciudadano, Entrevista realizada el 15 de marzo de 2013)

El debate acerca de si la demanda del movimiento tendría que ser sobre una clara oposición a la militarización o la demanda por la paz, estuvo presente no solo con este acontecimiento sino cuando Javier Sicilia visitó la ciudad en el marco de la Caravana del Consuelo, de la Esperanza y de la Paz como veremos más adelante. Además del debate permanente que sostuvieron con organizaciones no gubernamentales, los y las jóvenes movilizados buscaron diferenciarse de otros grupos organizados que se movilizaron por la inseguridad que se vivía en la ciudad pero exigiendo mayor presencia del ejército en las calles como sucedió con el movimiento de blanco (Méndez, 2009). Esta diferenciación era posible observarla también en los repertorios de acción. Mientras que el movimiento de blanco liderado por el tercer bloque de organizaciones marchaba con autoridades, camisetas blancas $\mathrm{y}$ en silencio, los jóvenes del primer bloque marchaban cerrando el paso, vistiendo de militares y burlándose de su accionar, reivindicando la alegría y la carnavalización de la protesta.

Una de las acciones que realizaron, fue la organización del Foro con Madres ${ }^{6}$. Militarización, Violencia y Derechos Humanos

6 “Con madres" es una expresión empleada en Ciudad Juárez para dar cuenta de algo que se hace con ganas. realizado el 12 de marzo de $2010^{7}$ en la Unam. A través de este foro, los/as jóvenes buscaron dar cuenta del fracaso de las políticas de seguridad, a partir de las experiencias de las madres de jóvenes asesinados/as y desaparecidos/ as. En las distintas intervenciones, las madres expresaron públicamente el duelo y denunciaron las injusticias cometidas en los casos de sus hijos e hijas a la par que buscaron reinvidicar sus nombres y su memoria. Durante todo el evento evidenciaron la criminalización de los y las jóvenes, el despojo, la impunidad y la represión por parte del Estado en distintas regiones del país. En este proceso se generó un diálogo intergeneracional, del que emergió una "comunidad emocional", desde la cual fue posible comunicar las experiencias de sufrimiento vividas por la violencia. La expresión pública de estas experiencias mostraron un importante potencial político si consideramos que allí se recompone la "acción de la persona como ciudadana, como partícipe de una comunidad política" (Jimeno, 2007). La experiencia compartida de las madres sin hijos, hizo que este espacio no fuera la sóla expresión del duelo en público, sino que se constituyó en un espacio desde el cual valorar las distintas luchas y también para denunciar una vez más que la estrategia de militarizar al país era errónea. Alrededor del foro se hizo un llamado permanente a la solidaridad y a movilización frente a la militarización, la violencia y la injusticia a través de acciones performáticas, tomando los espacios abiertos de la universidad y realizando siluetas en memoria de los y las jóvenes asesinados y desaparecidos en la ciudad. Mediante estas acciones buscaron sacudir a los jóvenes de la capital del país que por momentos parece vivir al margen de la coyuntura nacional.

7 Allí estuvo presente Rosario Ibarra diputada y miembro del Comité Eureka, Patricia Duarte y Martha García de la guardería $\mathrm{ABC}$, Cecilia Figueroa, integrante del Sindicato Mexicano de Electricistas, Luz María y Patricia Dávila, madre y tía de Marcos y José Luis, asesinados en Villas de Salvárcar, María de Jesús Álvarez de la asociación de padres y víctimas de sucumbios, Alicia Ramirez esposa de los mineros de Sombrerete Zacatecas, Sara Salazar del Valle de Juárez, Martha Pérez del Frente de Pueblos en Defensa de la Tierra. También estuvieron presentes Consuelo Valenzuela, Francisca Corrales y Patricia Cervantes de Justicia para Nuestras Hijas, Olga Esparza y Bertha García de Nuestras Hijas de Regreso a Casa, Gloria Zúñiga, madre de dos hijos desaparecidos a mano del ejército, Carmen Morales madre de un estudiante de medicina de la UACJ de Ciudad Juárez. 


\section{"JUÁREZ NO ES CUARTEL, FUERA EJÉRCITO DE ÉL". JÓVENES CONTRA LA MILITARIZACIÓN Y LA VIOLENCIA EN CIUDAD JUÁREZ}

Posteriormente, convocaron al Foro Internacional Contra la Militarización y la Violencia que se realizaría el 29, 30 y 31 de octubre de 2010 en la Universidad Autónoma de Ciudad Juárez. En este foro se trataría el "juvenicidio, la violencia institucionalizada, exterminio de grupos vulnerables, el feminicidio", así como "las luchas sociales contra la violencia, la violencia económica y la violencia ambiental". Además de las mesas de análisis se planearon conferencias, talleres, eventos culturales, testimonios, manifestaciones públicas y un concierto. Sin embargo, el evento no pudo realizarse debido a que la Policía Federal le disparó a Darío Alvarez, estudiante de 19 años de sociología quien se encontraba en las instalaciones de la universidad durante la onceava Kaminata contra la Muerte que abría el evento. Este acontecimiento generó una fuerte indignación por parte de la comunidad universitaria, que recurrió a la toma de las instalaciones:

Las instalaciones de la dirección de ICB (Instituto de Ciencias Biomédicas) fueron tomadas en una situación de emergencia, porque cuando la policía federal nos dispara, nosotros obviamente buscamos refugio en la universidad donde está pactado el foro y la policía federal está rondando alrededor de la universidad... Esto vuelve a poner en la agenda nacional la cuestión de la lucha contra la militarización en Juárez. (Gero Fong, activista Frente Plural Ciudadano, Entrevista realizada el 15 de marzo de 2013)

En los comunicados públicos y en rueda de prensa, reiteraron una vez más que en Ciudad Juárez no hay una guerra contra el narcotráfico y la presencia de las fuerzas militares son parte del problema y no la solución. Luego de la toma, continuaron las protestas en donde los estudiantes y otros miembros de la comunidad universitaria se apropiaron del discurso de la desmilitarización y demandaron la salida de las policías militarizadas de la ciudad ${ }^{8}$.

Luego de estos hechos locales, se producen una serie de acontecimientos nacionales que

8 Marcha comunidad universitaria, 3 de noviembre de 2010. https:// www.youtube.com/watch?v=1vLS_UC9bU8\#t=168 vuelven a poner a Ciudad Juárez en el centro de la escena nacional. Esta vez, como resultado del anuncio de la Caravana del Consuelo encabezada por Javier Sicilia del Movimiento por la Paz con Justicia y Dignidad (MPJD), que iniciaría en Cuernavaca el 4 de junio y terminaría en Ciudad Juárez el 10 de junio de 2011, considerada por Sicilia como el "Epicentro del dolor" para la firma del Pacto Nacional por la Paz".

Frente al anuncio de la caravana los y las jóvenes del Comité Universitario de Izquierda que pertenecían al Frente Plural Ciudadano, viajaron a Cuernavaca para sumarse a la caravana y a las discusiones que le darían cuerpo al Pacto. La idea era promover los temas que ya venían trabajando dentro del movimiento social, en lo referente a la demanda por la desmilitarización del país y de promover el no pacto con Calderón.

Antes del inicio de la caravana, se vislumbraban las tensiones entre la postura del MPJD orientadasalanegociacióneinterlocución con el gobierno federal. Esta postura no era exclusiva de los grupos de jóvenes de izquierda en Ciudad Juárez, sino también era compartida por otras organizaciones locales y nacionales. En efecto, Organizaciones de la Sociedad Civil, pertenecientes al segundo bloque de organizaciones movilizadas en ciudad Juárez, señalaron que en la firma de dicho pacto, eran bienvenidos los y las ciudadanas mexicanas menos los funcionarios gubernamentales, particularmente Felipe Calderón (De la redacción, 2011).

Durante la caravana, estas posturas no se modificaron y terminaron por generar rompimientos como sucedió después de la firma del Pacto en Ciudad Juaréz. A pesar de que al llegar a Ciudad Juárez se hicieron mesas de trabajo para construir un pacto, al día siguiente Sicilia se deslinda del Pacto en El Paso, Texas (Urrutia \& Villalpando, 2011). De acuerdo con Daniela Rea, periodista mexicana, la gente en Ciudad Juárez sintió que este acto fue una burla (Gordillo, 2015). Posterior a

9 Esta caravana parte de Cuernavaca hacia Ciudad de México, Toluca, Morelia, San Luis Potosí, Zacatecas, Durango, Saltillo, Monterrey, Torreón, Chihuahua y Ciudad Juárez. En el camino hubo diálogo y se recogieron testimonios de víctimas de la violencia. 
estos acontecimientos, si bien el MPJD sostuvo reuniones públicas con el ejecutivo nacional y promovió la formulación de la Ley General de Víctimas, su capacidad de movilización se diluyó.

Después de estos acontecimientos en relación con el movimiento social nacional, la fuerza que había alcanzando el movimiento social local para demandar la desmilitarización de la ciudad es mermado. Asimismo hay una importante ruptura entre las organizaciones locales, entre aquellas que buscaron el diálogo y las que se negaron al mismo las que terminaron por ser tachadas de radicales. En el fondo, estaba en disputa el diagnóstico acerca de las causas de la violencia y las formas de responder frente a la misma. En un intento por retomar el trabajo de movilización realizado, los y las jóvenes se aglutinan en lo que denominaron "los indignados de Ciudad Juárez" proponiendo una acción mediante la cual colocarían cruces blancas en espacios públicos para visibilizar la cantidad de homicidios registrados en la ciudad. Sin embargo, esta movilización fue duramente reprimida (Redacción Animal Político, 2011). En estas acciones, así como en las kaminatas kontra la muerte, se observan innovaciones en los repertorios de acción, que se sumaron a los tradicionales repertorios, en donde a través la carnavalización de la protesta y la ocupación del espacio público, buscaron dirigirse a las personas de a pie de una manera diferente buscando romper con la inmovilidad causada por el miedo a la violencia y a la represión.

Luego de un periodo de latencia, muchos de los activistas que participaron en el movimiento en contra de la militarización y la violencia, confluyeron en el movimiento \#yosoy132 Juárez. Su participación en este movimiento les permitió continuar con la denuncia del proceso de militarización que se vive en el país compartiendo la experiencia vivida en Ciudad Juárez.

\section{Conclusiones}

A diferencia de otros lugares en el país en donde se experimentan altos índices de violencia e inseguridad en Ciudad Juárez se gestó un importante movimiento social que tuvo vinculaciones con organizaciones locales, nacionales e internacionales. En este movimiento, los/as jóvenes tuvieron una importante presencia, particularmente en la creación nuevos marcos de interpretación y repertorios de acción que se opusieron a los discursos oficiales que insistieron en afirmar que se estaba librando una guerra contra el narcotráfico que justificaba la presencia de fuerzas militares y posteriormente de las policías militarizadas en la ciudad.

En este sentido, buscaron formas de participación diferenciadas de los canales clásicos que recuperaron distintos repertorios de acción, que van desde el performance a las marchas en donde hubo una importante labor de uso y apropiación del espacio público, como ha ocurrido con los movimientos juveniles, en este último ciclo de movilización en América Latina (Aguilera, 2016; Vommaro, 2015).

También observamos la creación relaciones intergeneracionales que buscaron tender puentes entre los/as jóvenes y otros sectores organizados y no organizados, como sucedió con el segundo y tercer bloque de organizaciones locales, con el Movimiento por la Paz con Justicia y Dignidad y las organizaciones de madres con hijos e hijas asesinadas y desaparecidas. Estas relaciones no estuvieron exentas de tensiones en tanto que las posturas por parte de los y las jóvenes, particularmente aquellas que se negaron a sostener un diálogo con las autoridades, no fueron leídas contextualmente con lo cual fueron constantemente tachados desde una visión adultocéntrica de radicales.

A través de estas tensiones, las acciones por parte de los y las jóvenes al interior del movimiento dieron cuenta del conflicto social que generaba la presencia de las fuerzas militares y la política gubernamental para hacerle frente a la violencia y la inseguridad. También desafiaron la retórica que insistía en encasillar a "los daños colaterales" como constantemente se denominó a las víctimas de como actores pasivos, sino que demostraron la capacidad de agencia y la capacidad para movilizarse colectivamente. En este sentido desafiaron el miedo frente a un contexto que aparecía hostil no solo para los y las jóvenes sino también para las organizaciones sociales 


\section{"JUÁREZ NO ES CUARTEL, FUERA EJÉRCITO DE ÉL". \\ JÓVENES CONTRA LA MILITARIZACIÓN Y LA VIOLENCIA EN CIUDAD JUÁREZ}

y los defensores de derechos humanos. Exigir el derecho a la vida y también el derecho al duelo se constituyó en un importante motor para la movilización en un contexto en que las autoridades con apoyo de los medios masivos de comunicación transmitían la idea de que cada muerto más era un delincuente menos y no una persona que le hacía falta a su familia y a su comunidad.

\section{Lista de referencias}

Agudelo-Ramírez, A.; Murillo-Saa, L.; Echeverry-Restrepo, L., \& Patiño-López, J. (2013). Participación ciudadana y prácticas políticas de jóvenes en la cotidianidad. Revista Latinoamericana de Ciencias Sociales, Niñez y Juventud, 11(2), 587-602. doi:10.11600/1692715x.1120250612

Aguilera, Ó. (2016). Movidas, movilizaciones y movimientos: cultura política y políticas de las culturas juveniles en el Chile de hoy. Santiago de Chile: Ril Editores.

Alvarado, S. V., Martínez, J., \& Muñoz, D. (2009). Contextualización teórica al tema de las juventudes: una mirada desde las ciencias sociales a la juventud. Revista Latinoamericana de Ciencias Sociales, Niñez y Juventud, 7(1), 83-102.

Ballinas, V. (2010, febrero 5). Seguridad en todos los puntos de la ciudad, demandan ONG. México, D. F.: La Jornada.

Cárdenas, L. (2014, junio 27). Controlling violence, not drugs, becomes key strategy in Juárez. Recuperado de:

h t t p : // n e w s pa per tre e.co m/ articles/2014/06/27/controlling-violencenot-drugs-becomes-key-strategy-in-juarez

Castillo, G., \& León, G. (2010, febrero 4). La Jornada: advierten grupos juarenses que actuarán por su cuenta. México, D. F.: La Jornada.

Castillo, N. (2009). Capital social y nivel de cohesión social en Ciudad Juárez. Diagnóstico sobre la realidad social, económica y cultural de los entornos locales para el diseño de intervenciones en materia de prevención y erradicación de la violencia en la región norte: el caso de
Ciudad Juárez, Chihuahua. Ciudad Juárez: Chih.

Cefaï, D. (2008). Los marcos de la acción colectiva: definiciones y problemas. En A. Natalucci (Ed.), Sujetos, movimientos y memorias: sobre los relatos del pasado y los modos de confrontación contemporáneos (pp. 49-79). La Plata: A Margen.

De la redacción (2011, mayo 13). Pacto con la sociedad, no con autoridades; "acuerdo para la refundación del país", la postura de las OSC locales para la reunión con Sicilia en Juárez el 10 de junio. Ciudad Juárez: Chih. Recuperado de: http://www.arrobajuarez.com/notas. php?IDNOTA=21476

Díaz, L. (s. f.) Breve análisis de la relación Estado-movimiento social en contextos de extrema violencia: Ciudad Juárez durante el periodo de militarización. Ciudad Juárez: Mimeo.

Gaytán, B., Olivas, J. de D., Minjares, G., \& Coronado, M. (2010, marzo 2). Convocan aqui a marchas vs. la violencia. Ciudad Juárez: El Diario de Juárez.

Gordillo, J. (2015). Ley General de Victimas, un resultado político del Movimiento por la Paz con Justicia y Dignidad. México, D. F.: Colegio de México.

Gúber, R. (2004). El salvaje metropolitano: reconstrucción del conocimiento social en el trabajo de campo. Buenos Aires: Paidós.

Jimeno, M. (2007). Lenguaje, subjetividad y experiencias de violencia. Antípoda. Revista de Antropología y Arquelogía, (5), 169-190.

http://www.animalpolitico.com/2011/06/ caravana-por-la-paz-sicilia-refrendavoluntad-de-dialogo-con-autoridades/

Melucci, A. (1991). La acción colectiva como construcción social. Estudios Sociológicos, IX(26), 357-364.

Méndez, A. (2009, marzo 2). Surge el Movimiento Blanco, grupo civil sobre seguridad, empleo y educación. México, D. F.: La Jornada. Recuperado de: http:// www.jornada.unam.mx/2009/02/03/index. php? section $=$ politica $\&$ article $=014 \mathrm{n} 2 \mathrm{pol}$

Meyer, M., Brewer, S., \& Cepeda, C. (2010). Abuso y miedo en Ciudad Juárez: un 
análisis de violaciones a los derechos humanos cometidas por militares en México. Washigton, D. C., México, D. F.: Wola-Prodh.

Moloeznik, P.; Shirk, D., \& Suarez de Garay, M. E. (2011). Diagnóstico integral de la Policía Municipal de Ciudad Juárez. San Diego: Justice in Mexico Project.

Monárrez-Fragoso, J. (2009). Trama de una injusticia: feminicidio sexual sistémico en Ciudad Juárez. Tijuana: Colegio de la Frontera Norte, Porrúa.

Murillo, C. (2014). Fronteras por la paz: Juárez dialoga. Ciudad Juárez: Chih. Recuperado de: http://juarezdialoga.org/ls-articulistas/ fronteras-por-la-paz/

Nateras, A. (ed.) (2016). Juventudes sitiadas y resistencias afectivas. Ciudad de México, Barcelona: UAM Iztapalapa, Gedisa.

Pedraza, H. (2008). Apuntes sobre el movimiento armado socialista en México (1969-1974). Noésis, 17(34), 92-124.

Redacción Animal Político (2011, noviembre 2). Consignan a 32 «indignados» de Ciudad Juárez tras represión policial. México, D. F.: Animal Político. Recuperado de: http:// www.animalpolitico.com/2011/11/policiade-ciudad-juarez-reprime-manifestacioncontra-violencia/

Reguillo, R. (2000). Emergencia de culturas juveniles: estrategias del desencanto. Bogotá, D. C.: Norma.

Somers, M. (1994). The narrative constitution of identity: A relacional and network approach. Theory and Society, (23), 605649.

Tarrow, S. (1997). El poder en movimiento: los movimientos sociales, la acción colectiva y la política. Madrid: Alianza Editorial.

Tilly, C. (2002). Repertorios de acción contestataria en Gran Bretaña: 1758-1834. En M. Traugott (Ed.), Protesta social: repertorios y ciclos de acción colectiva (pp. 1-47). Barcelona: Hacer.

Urrutia, A., \& Villalpando, R. (2011, junio 11). La Jornada: fin de la guerra antinarco, exigen ciudadanos en el pacto nacional. Ciudad de México: La Jornada.

Urteaga, M. (2010). Género, clase y etnia: los modos de ser joven. Los jóvenes en México. México, D. F.: FCE-Conaculta.
Valenzuela, J. M. (Ed.) (2015). Juvenicidio: Ayotzinapa y las vidas precarias en América Latina. Guadalaja, Tijuana: NED Ediciones, Iteso, Colef. Recuperado de: https://books.google.com.mx/ books?id=zh8ACwAAQBAJ

Vommaro, P. (2013). Hacia un abordaje de las relaciones entre políticas y juventudes en América Latina a partir de la noción de generación. Recuperado de: http://www.perfiles.cult.cu/article_c. php?numero $=11$ \&article $\mathrm{id}=301$

Vommaro, P. (2015). Juventudes y políticas en la Argentina y en América Latina: tendencias, conflictos y desafios. Buenos Aires: Grupo Editor Universitario. 